\section{A Rationale for Using Computers in Science Education}

\author{
James D. Ellis
}

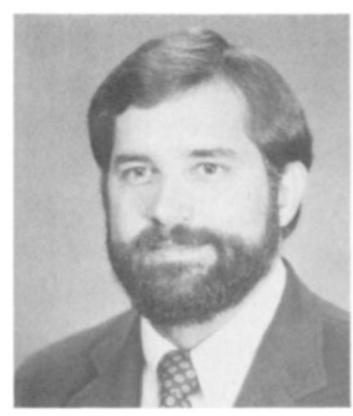

James D. Ellis is project director for educational computing at the Biological Sciences Curriculum Study, Colorado Springs, CO 80903. He is also director of the BSCS School Health Education Project (funded by the Gates and Piton Foundations). He holds a B.A. from the University of Kansas and M.A. and Ph.D., also from the University of Kansas, in curriculum and instruction. His teaching experience includes positions in a middle school as well as at the University of Kansas, University of Texas at Austin, and University of Colorado at Colorado Springs. He currently serves as Regional Director of the Colorado Biology Teachers Association and was the program director for the 1983 AETS convention in Dallas. Dr. Ellis' most recent publication is "Educational Technology: A Force for Change" (with P. Kuerbis) in the 1984 NSTA Workbook, Redesigning Science and Technology Education.
Science teachers are finding that they too are being involved in the revolution affecting society. The United States is in a rapid state of change from an industrial-based society to an information society. Eric Ashby labeled this the "fourth revolution, comparing the impact with the advent of Gutenberg's printing press" (National Science Foundation 1979).

Information is essentially the major national resource of all countries. Every country has the potential to participate in the global economy providing it knows how to manage information. The computer is a sophisticated memory bank with great facility at organizing and retrieving information. Rapid advances in computer technology are the driving force behind the information revolution. That technology, for the first time, makes it cost effective for anyone to access great volumes of detailed information. It is the application of the information, that is, knowledge utilization, that solves the problems confronting society.

Public interest in the information revolution is reaching a critical level. Several state and national committees are investigating the crisis in science education in response to the changing world economy. This mass movement for change is resulting in a reexamination of the foundation of science education, and there is a current restructuring of the goals and methods of science teaching. Many of the goals being emphasized are not new. However, the focus on technology education does represent a significant departure from past directions, and computer technology is receiving high priority among the new topics of study. As a result, science educators are now asking: Why use computers in the classroom?

The rationale for using computers in the classroom is based on our increasing dependence on the creation, use, and communication of information for economic and social well-being. As a result, computing is being recognized as the fourth basic skill, along with reading, writing, and arithmetic (National Science Foundation 1979).

This article will focus on the recommendation for increased use of computers in the schools and will develop a rationale for the use of computers in the science classroom.

\section{Uses of the Computer}

Educational uses of the computer can be classified as tutor, tool, or tutee (Taylor 1980). Computer assisted instruction (CAI) is a label applied to using the computer as a tutor. Different CAI uses include drill and practice, simulation, gaming, and tutorial dialogue. Drill and practice are by far the most common uses of the computer in the classroom. They are used to assist the student in mastery of basic skills. Drill and practice allow for concentrated remediation in diagnosed areas of weakness. 
Simulations and games are motivational and highly interactive methods of providing instruction that enrich educational experience. Simulations of complex real world phenomena allow the student to manipulate abstract concepts in a more concrete manner. The student is able to interact with phenomena that previously were not accessible due to safety, time, expense, or space restrictions. Games enhance instruction by providing motivation to learn through competition. Video arcade formats promise to increase the involvement of the learner in otherwise unexciting material.

The tutorial approach is a truly exciting form of CAI. At present, there is little software that allows the use of the computer in an interactive, Socratic dialogue. However, pilot studies are underway that apply the field of artificial intelligence to educational computing; those studies will likely allow for dialogue between the computer and the pupil.

The focus on the computer as a tool or tutee is more interesting to science educators. Use of the computer as a tool includes computer managed instruction (CMI), computer based testing (CBT), word processing, information retrieval, data gathering, and data analysis. Ragsdale (1982) suggests that in the next decade CAI may decrease in importance while use of the computer as a tool will increase. The computer will be used as a word processor, a calculator, and a data manager in all content areas. In science, students will use the computer to gather real-time data with various temperature, light, sound, and tactile sensors (Tinker 1981). Those data will be more accurate, from larger samples, and gathered over more extreme time spans than is possible with current procedures. Data will be summarized and analyzed with statistical programs, displayed with graphing programs, and reported with word processing programs. Activities will include individualized, small group, and large group work and will be based upon individualized learning objectives. Those are not new approaches, but CMI will make possible the individualization of instruction by handling the necessary, immense recordkeeping.

Philosophers of educational computing stress the important role of the computer as a tutee. Papert (1980) believes the computer should be used to change how and what students learn. The computer can be used to create a learning environment wherein students can discover the underlying relationships, rules, principles, and laws of a discipline. The goal is to improve the learner's problemsolving abilities. By teaching the computer to perform some task, the student must divide that task into its component parts. In so doing, the learner is forced into thinking in a structured form and, it is hoped, improves in this form of problemsolving (Dwyer 1980).
The most appropriate educational uses are yet to be determined. That determination depends on a variety of factors, not the least of which is the importance the teacher attaches to computer use. The remaining sections of this article will provide a rationale for computer use in the schools.

\section{Societal Need}

The answers to the question: "Why does society need educational computing?" derive from national needs. Those needs involve economics, computer literacy, and equality of opportunity.

Economic need-The economic need results from our rapid change to an information society, economic trends related to that change, present and predicted employment trends, and indicators of world economic competition. The information technology sector of our society has grown rapidly since World War II. The information industry now accounts for more than $60 \%$ of the economic activity of the United States, and the use of computers has increased rapidly in the past two decades. The information industry is growing at a rate of more than $20 \%$ per year (Office of Technology Assessment 1982); that has a profound impact on the U.S. employment trends and economic status.

Employment trends over the past few decades have paralleled the changes in the productivity bases of our society. The United States has progressed from an economy based primarily on agriculture, through one based on heavy industry, to the current, information-centered economy. At present more than $50 \%$ of the U.S. labor force is engaged in information occupations. Experts predict that more than $65 \%$ of the work force may have information-related jobs by the year 2000 (American Association for the Advancement of Science 1982). The result will be a premium on literacy in science, technology, and knowledge utilization. Workers lacking those skills will need retraining to find a place in the information society. "Lifelong retraining is expected to become the norm for many people" (Office of Technology Assessment 1982).

The transformation of the U.S. into an information society is having a significant impact on our place in the world economy. A study by the National Science Foundation (NSF) that reported on the relationship between world trade and engineering training showed that Japan's percentage of the world trade nearly doubled from 1963 to 1977, while the U.S. portion declined by nearly 25\% (National Science Foundation 1981). During the same period Japan produced 2.6 times as many engineers per relevant age group as did the U.S. In contrast to the U.S., where $5 \%$ of the baccalaureate and master's degrees are in engineering, in Japan $20 \%$ of baccalaureate degrees 
and $40 \%$ of master's degrees are in engineering. The NSF (1981) also reported that "between the same years (1963 to 1977) productivity increased in the manufacturing industries of the United Kingdom, West Germany, Japan, and the U.S. (using 1963 as the base year) by $51 \%, 114 \%, 197 \%$, and 39\% respectively." NSF (1979) summarized the situation as follows:

The United States, the country that developed and applied solid state and electronic technology, finds itself in the position of having almost all radios and television sets being produced in foreign countries. Unless the government, business, and universities act together, leadership in information technologies may be lost in the same way that our position in electronics was lost and our automobile market challenged.

The need for computer literacy-Computer literacy is rapidly becoming one of the basic skills required for full participation in the emerging information society. The NSF (1979) points out that "as the computer becomes a part of the home, school, and business landscape, people will need to know how to make intelligent, productive, and creative use of it." Hurd (1982) states that "quite likely, the 'disadvantaged' learners of the near future will be those who lack the skills to exploit microelectronic information resources and synthesize the findings."

As the information economy grows, greater numbers of citizens will require computer literacy. Experts predict that by 1985 , there will be 2.5 million microcomputers in offices around the country, one for every four clerical workers. Already a secretary who has skills in word processing earns at least $\$ 50$ more per week than one who lacks those skills (Business Week 1981). A study of 40 large cities in California found that " $30 \%$ of 'countertop bureaucrats' (such as utility clerks) use a computer daily . . . only $6 \%$ of policy makers use computers on a daily basis . . Probably by the end of the decade, that $30 \%$ figure of 'countertop bureaucrats' will be true of all levels of the workforce" (Business Week 1981). Automation and robots may replace as many as 45 million workers during the next 20 years. That is not expected to increase unemployment, but it will require that employees have different skills. "Ultimately the nation's education system will have to prepare future workers for functioning in an electronic society" (Business Week 1981). Public education must ensure computer literacy.

The need for equality of opportunity-The rapidly changing requirements for employment in the information industry bring with them important concerns for equality of career opportunities. Presently, computer literacy is more easily attained by affluent males. "This means that equality of career opportunity will become a hollow promise if our educational system reserves computer training and experience for the already affluent" (National Science Foundation 1979). Equality of opportunity is a politi- cal rather than an educational issue. However, equality of opportunity has been one of the principal goals of federal involvement in education. Perhaps it is not feasible to ensure true equality of opportunity, but equal access to careers is a well established public policy in our society. Ensuring that all students have opportunities to develop computer literacy, regardless of gender, race, or creed, will promote equal access to the many new careers in the information society.

Women are grossly underrepresented in the fields of math, science, and engineering. Even though women now make up to $40 \%$ of the work force, they represent only $2 \%$ of all engineers and less than $10 \%$ of persons in computer sciences (Education USA 1983). There is a trend toward a greater share of earned degrees in science awarded to women (National Science Foundation 1982). However, the percentage of degrees awarded to women in physics, math, and engineering still is less than $10 \%$ of the total awarded.

The United States is failing to utilize fully one of its most valuable resources for the future. Human capital theory suggests that economic benefit is derived from appropriate development and use of human potential (Office of Technology Assessment 1982). With the current and predicted shortage in science- and mathrelated fields, such underutilization of women is disturbing. The greatest immediate potential pool of workers to fill the employment needs of the information society is women. The public schools share the responsibility for ameliorating this inequity.

\section{The Needs of Educators}

Public education serves society by transmitting skills, knowledge, and values to citizens, thus enhancing their contribution to the nation's well-being. Educational goals and objectives are a reflection of societal needs. Educational needs for computing are founded on: the emergence of new goals, changing patterns of education, cost effectiveness, and the need for improvement in quality.

New goals-The increasing need for computer literacy has caused a reexamination of educational goals. Many state, local, and national committees are in the process of examining educational goals and programs in computer literacy. The Minnesota Educational Computing Consortium has long been a leader in this area. California, North Carolina, Texas, Wisconsin, Colorado, and other states have or are in the process of developing state guidelines for computer literacy. National organizations, such as the National Council of Mathematics Teachers and the National Science Teachers Association, are recommending guidelines for computer literacy. Those, as well as other, more general recommendations for science, math, and technology education, may lead to significant 
changes in educational programs and practice in public schools.

Changing patterns-Changing patterns of education dictate a redirection of educational practice. Those patterns pervade all aspects of society ranging from the home to business and industry. Educational computing can provide a method of providing instruction in diverse settings to meet a variety of needs.

Education is in the process of redefinition in response to the developing crisis in public schools. New patterns of education are emerging in society. There is increasing use of libraries and museums by the public. Business and industry are deeply involved in education. Seventy-five percent of U.S. companies provide some in-house courses for employees and spend $\$ 30$ billion annually for educational programs, staff, and materials. Already, after-hours schools are opening to provide remediation and enrichment experiences. The dominant focus of learning is on lifelong learning, retraining, and updating knowledge. The goal is learning how to learn.

The computer opens up possibilities for instruction that were not previously viable. As mentioned already, individualization of instruction is more easily obtainable. Many small school systems have only a few students interested in pursuing advanced topics in science, math, or other disciplines. It is not possible for those school districts to hire a physics teacher or calculus teacher for these few students. A combination of information technologies, including educational television and CAI, can help provide small groups of learners with new educational opportunities. Those students could work individually or in small groups under the supervision of a teacher/mentor. Those new information technologies offer the possibility of broadening opportunities for in-depth, independent study in advanced topics.

Cost effectiveness-The public education system is faced with the problem of offering ever-expanding educational services to an increasingly diverse population. Public schools are charged with the social responsibility to ensure equality of opportunity for women, minorities, handicapped, and other disadvantaged citizens. Individualized instruction, the suggested solution to providing appropriate education for all citizens, is very time consuming, difficult to implement, and costly. How can educational institutions provide quality education to meet the needs of an increasingly diverse population and simultaneously contain the cost?

Cost effectiveness is a major concern for public education.

Costs for labor intensive education and training methods continue to climb faster than the inflation rate, while costs for information technology continue to drop precipitously. Costs of education are increasing twice as fast as the rate of increase of revenues for edu- cation. Thus, in 10 years, if inflation continues at its present rate, education institutions will have only one half the revenues (in real terms) that they have now (Office of Technology Assessment 1982).

The cost effectiveness of computing has increased more than a million times in the interval since World War II. That is a doubling rate of two years (National Science Foundation 1979). Even at today's cost/benefit ratios, the use of computers for basic skills and special education problems on a remedial level is more cost effective than traditional methods. As more sophisticated hardware and courseware become available at lower prices, computers will become cost effective in a variety of educational settings.

Improving education-Professional educators have a responsibility to explore any innovation that promises to increase their effectiveness or efficiency. Advances in educational computing, videodisc technology, and other information technologies promise to improve the quality of education by relieving teachers of mundane tasks and by enriching the educational experiences of learners. Computers can assist in routine data management tasks such as attendance, recordkeeping, test generation, testing, test grading, individualization, equipment inventory, and reportingsystems.

Individualization of instruction has been unrealized because of the difficulty of managing the procedural system. Computers can be used to pretest students, diagnose areas of weakness, suggest appropriate instructional activities, monitor student progress, provide appropriate feedback, post test, and keep records of results. The teacher can be freed to work with large groups, small groups, and individuals. The computer will not replace the teacher, but will serve as a tool to assist the teacher in managing instruction.

\section{Fear of Educational Computing}

It is not possible to consider educational computing without describing probable impediments. The fear of educational computing is that after a great investment it will fail. That is a realistic concern. The success of educational computing depends on the extent of acceptance by students, teachers, administrators, and parents.

There are many barriers to the acceptance of educational computing in the schools. Students, perhaps, represent the least significant barrier to implementation. They are already very comfortable with computers in the form of video games. However, will they accept a major role for computers in education? Do students have the requisite knowledge and skill to take full advantage of the computer? Preliminary research indicates that students can be motivated to learn using the computer.

Teachers and administrators are wary of educational 
innovation and are apprehensive about committing large amounts of time and funds to new goals and methodologies. At present, few teachers are well trained in educational computing, even though many teachers are voluntarily seeking computer literacy. Lack of teacher training is a significant barrier to large-scale implementation of educational computing. It will take massive local, state, and federal funding of inservice teacher training to upgrade the level of computer literacy of teachers.

Educators are concerned about the quality of education provided by computers. This is a twofold problem. First, there is little quality software available in most subject areas. Second, the software that is available often emphasizes inappropriate uses of the computer. The quality of courseware is improving rapidly, however. With proper incentives commercial software vendors will produce abundant, quality CAI programs. However, CAI programs often represent too narrow a focus of the use of educational computers, and more emphasis is needed on the development of programs that expand and enhance current educational practice. If the computer is to be used as an enrichment center that supplements core instruction and is available only to a few students, then it becomes a very costly learning center relegated to the corner of the classroom.

Educators are concerned about the cost of implementing educational computing. At present, providing enough computers to allow for all possible educational uses may be impossible. However, with the rapid decrease in costs for computing it may become feasible to make available sufficient computers to meet the needs. Computers are more efficient and equally effective at providing remedial basic skills instruction (Kulick, Kulick, and Cohen 1980). They can serve as a tool to enable teachers to manage instruction more effectively. Cost will not be the most significant barrier to implementation.

Perhaps the most significant barrier to implementation of any educational innovation is teacher resistance to change. Teachers want to know: How is this change going to affect me? Will this change require me to change behaviors that have proven effectiveness? Will I be replaced by a computer? Educational computing has the potential to restructure the way we teach. Some teachers and schools will welcome the new innovation and adapt easily. Others will resist. However, if educators are to fulfill their responsibilities, they will not only have to adapt to requirements of the information society, but also assist all citizens in making the transition.

\section{Computer Literacy in Science Education}

Although computer literacy is widely acknowledged as an important goal for all students, there is considerable confusion about its meaning. Luehrmann (1981) points out that the definition and objectives for computer literacy will dictate the curriculum. He emphasizes that all too often computer literacy is restricted to computer awareness, when it should also encompass "the ability to do computing." A computer literate person must be able to use the computer to solve problems encountered in everyday life.

Computer literacy can best be developed in subject areas. Restricting computers to classes in computer literacy removes the skill from the application. That is similar to restricting reading just to reading class. The skill obtains relevance in its use in a realistic problem situation.

The controversy over whether to require computer programming skills of all students focuses on only one aspect of computer literacy. Few daily users of computers write computer programs. It may be true that learning programming languages fosters deeper understanding of computer function and enhances problemsolving abilities. However, mastery of programming language is not sufficient as an end in itself. It is the application of the programming skill to solve a realistic problem that provides relevance. Perhaps the development of the basic knowledge and skills necessary to use a computer, including computer languages, can best be offered as separate instruction. However, application of that knowledge can best be accomplished in specific subject areas.

The science curriculum offers many opportunities to use the computer in meaningful ways. It is an area rich in problemsolving situations appropriate to computer applications. Concepts such as population growth represent systems of interacting variables. Full understanding of those interactions is difficult to develop through conventional teaching techniques. Dealing with each variable in isolation gives an incomplete picture of the relationships, and demonstrating scenarios of the impact of manipulating one or more variables takes too much time. The computer offers new methods of demonstrating complex systems by allowing manipulation of the variables in a computer simulation of a system and getting nearly immediate feedback of the results. Concepts in genetics, ecology, and population growth have all been adapted for computer simulations.

\section{Training Science Teachers to Use Computers}

The strategy of improving the quality of teacher training to achieve the goal of computer literacy for students is justified in two ways. The first is that there is currently a low level of teacher knowledge and skill about educational computers. The second is that the teacher plays a key role in instruction.

Rarely has a change of such magnitude confronted 
education as that of educational computing. The rapid growth in numbers of classroom computers has immediate implications for teacher training. As many as $85 \%$ of the nation's science teachers have been teaching for more than one year, and few of those teachers have had formal preservice education in how to use the computer in the classroom. However, many will be confronted with the problem commonly brought to the attention of any teacher educator known to be knowledgeable about instructional applications of microcomputers. That problem is summarized by this scenario:

My principal just notified me that a microcomputer is going to be provided to the science department. He wants me to learn all about how to use it in the classroom. He has some funds to order a couple of commercial software packages and would like me to choose them. He expects me to develop some additional software on my own. What do I do? Where do I begin?

Little can be gained by the purchase of a microcomputer for the science classroom if it is not incorporated into instruction. It must supplement and reinforce existing programs. Teachers must learn to use the computer in instruction, just as they have learned to use textbooks, lectures, films, television, and field trips. However, as Robert F. Watson (1983) recently pointed out, few teachers have been trained in how to use a computer for instructional purposes.

Preservice and inservice teacher training programs must provide for the development of computer literacy. Computer literacy for teachers is defined in the same manner as it is for students: teachers need to be able to use the computer to do something. Most often, teachers need to be able to use the computer for instructional purposes. Although many schools of education and some school districts provide training for teachers in how to use the computer, that training often models university-level courses in instruction to computer science or computer literacy courses for public school students. That is, current training teaches students about the computer, how to operate the computer, and often how to program. Those courses are typically offered outside of the subject area or methods courses. That can be misleading, for a fully computer literate teacher must understand both the technique and its application in instruction.

Knowing the technique of instructional computing involves knowledge about a microcomputer, different ways the computer can be used in instruction, and other, more generic teaching skills such as planning instruction and evaluating materials. Those skills are not limited by what is to be taught. The decision as to what method and material is best to teach a specific concept is, however, bound by subject area.

This second skill-how to use the microcomputer as a technique of instruction-is best developed in the subject area component of teacher training. Just as the best way to teach students computer literacy is to have them apply the skill to a realistic and relevant problem, the best way to train teachers to use computers in the classroom is to provide opportunities to apply the skill in subject areas. Because no educator is expert in all disciplines, subject area experts should be available to assist the teachers in identifying how to use the computer most effectively in their specialty.

Materials must be developed for training teachers in the most appropriate uses of microcomputers in the science class. Those materials must be infused in to preservice and inservice science education courses. The materials must be designed with the flexibility to accommodate teachers with different levels of knowledge about educational computing, teaching at different grade levels, and at different levels of career development, ranging from preservice to inservice. The materials should be organized to allow for mastery by independent study or by work in large groups. The focus of the materials should be able to enable teachers to master the skills necessary to use the computer successfully with a science class.

\section{Appropriate Uses}

The question of whether to use computers in schools is moot; the trend is clear. It is important, however, to identify and capitalize on appropriate uses of computers in education.

The computer is too costly to use to provide instruction that can be provided more effectively by a book or other methods, and the ease of writing drill and practice programs does not alone justify their use. Science educators have long deemphasized the importance of memorization of large bodies of factual information. Educational uses of the computer that offer promise include microworlds for exploring complex systems, simulations of real situations to enable expanded opportunities for in-depth investigation of phenomena, educational games that motivate the learner to master basic material, knowledge utilization systems to promote information processing via the computer, programming languages that promote problemsolving, computer based instrumentation that enhances data acquisition and analysis, and computer management of instruction to permit true individualization and to free the teacher to focus on interpersonal interaction.

\section{Summary}

The rapid transformation of our nation into an information society compels educators to establish computer literacy as an important goal. The economic tie between the successful transformation to an information society and the level of our nation's scientific and technological literacy is one justification for improvement in our science educational system. The 
escalating cost of education mandates use of the most efficient and effective methods of education. Educational computing can help solve those problems. It is the responsibility of science educators to ensure that educational computing is maximally effective in improving the nation's educational system.

Appropriate uses for educational computing must be validated through research and implemented in our nation's schools. Educational computing could fail to improve the quality of schooling if its use is restricted only to CAI drill and practice instruction. The most important factor in determining the level of implementation of educational computing will likely be the degree of acceptance by teachers.

\section{References}

Business Week. 1981. Changing 45 million jobs. August 13, 58-67.

DWYER, T. 1980. The computer in the school: Tutor, tool, and tutee. New York: Teachers College Press.

HURD, P.D. 1982. Problems and issues in precollege science education in the United States. Paper presented to the National Science Board; Commission on Precollege Education in Mathematics, Science, and Technology, July.
KULICK, J.A., KULICK, C.C., and COHEN, P.A. 1980. Effectiveness of computer-based college teaching: A metaanalysis of findings. Review of Educational Research 50(4):525-544.

LUEHRMANN, A. 1981. Computer literacy-What should it be? Mathematics Teacher 74:682-686.

National Science Foundation. 1979. Technology in science education: The next ten years-perspectives and recommendations. Washington, D.C.

1981. How the U.S. compares with other countries. Educational Leadership. Washington, D.C.: AAAS. 1982. Science and engineering education: Data and information. Washington, D.C.: NSF 82-30.

Office of Technology Assessment. 1982. Information technology and its impact on American education: Data and information. Washington, D.C.: Government Printing Office. LCN 82-600608.

PAPERT, S. 1980. Mindstorms: Children, computers, and powerful ideas. New York: Basic Books, Inc.

RAGSDALE, R.G. 1982. Computers in the school: A guide for planning. Ontario: Ontario Institute for Studies in Education Press. Informal series no. 45.

TAYLOR, R. 1980. The computer in the school: Tutor, tool, tutee. New York: Teachers College Press.

TINKER, R.F. 1981. Microcomputers in the teaching lab. The Physics Teacher. 74-105.

WATSON, R.F. 1983. Computer-based projects in science education: An overview. Journal of College Science Teaching 12(6):375-380.

\section{Join the Network}

Return this today and join the only professional association concerned exclusively with biology education. Membership in the National Association of Biology Teachers gives you access to committees, an annual convention, The American Biology Teacher, and much more.

$\square$ Please enroll me as a member of the National Association of Biology Teachers for just $\$ 30 .^{*}$ (This includes $\$ 15$ for a subscription to The American Biology Teacher.)

$\square$ Payment Enclosed $\square$ Visa $\square$ MasterCard Card No. Exp. Date

Sig. Name

Address

City, State, ZIP

*US, Possessions, \& Canada, in dollars drawn on an American bank. Foreign subscriptions to $A B T$ ONLY ARE \$(US)35, Int'l. Money Order. Allow 4-8 weeks for your first issue.

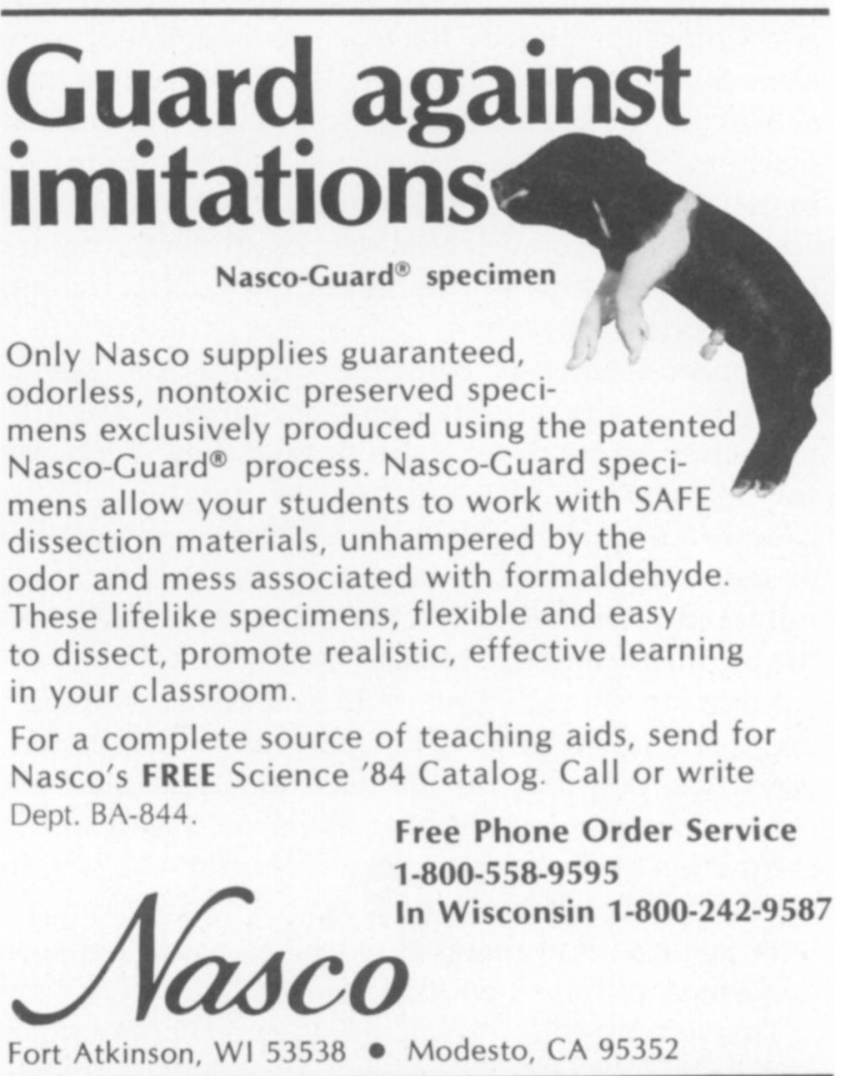

Fort Atkinson, WI 53538 - Modesto, CA 95352 